\title{
Upper Gastrointestinal Hemorrhage Secondary to Ectopic Spleen
}

Ectopic spleen is a rare entity (1). Clinically, it usually presents either with signs of acute abdomen or as an fairly painful apparent abdominal tumor of the chronic recurrent type. Only one previous case of ectopic spleen causing gastrointestinal hemorrhage has been described (2).

A 40-year-old man was admitted to our hospital due to signs of severe hypochromic anemia. Diagnostic endoscopy revealed a bluish semipedunculated polyp measuring $15 \times 10 \mathrm{~mm}$ on the posterior wall of the stomach, $7 \mathrm{~cm}$ below the cardia, with stigmata

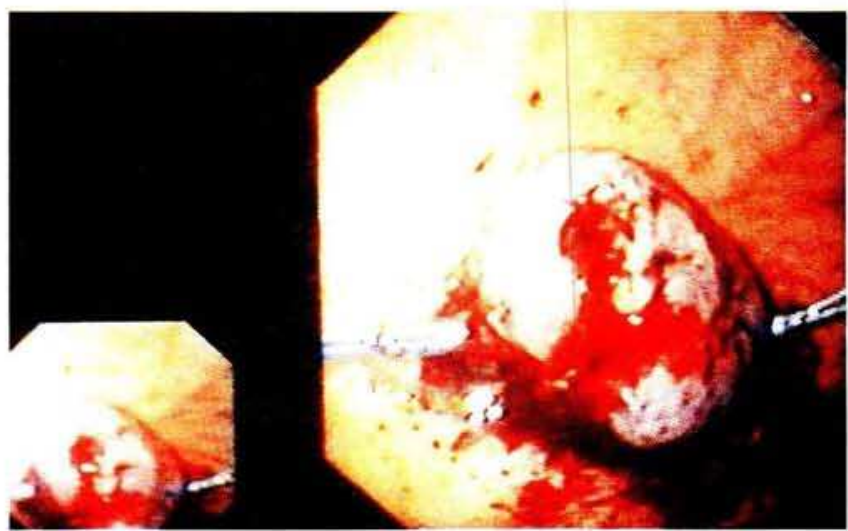

Figure 1: Endoscopic view of a gastric polyp measuring about $15 \mathrm{~mm}$ in diameter, with slight bleeding. of recent bleeding. No signs of other possible sources of bleeding were noted. Endoscopy also showed minor varicose veins around the base of the lesion (Figure 1). There were no endoscopic signs of portal hypertension. A detachable snare (ligating device) was applied to control the bleeding lesions. Five days after the ligation, necrosis and hemorrhage from the lesion was observed, and the patient underwent surgical excision. The pathology revealed an ectopic spleen (Figure 2). The postoperative course was uneventful.

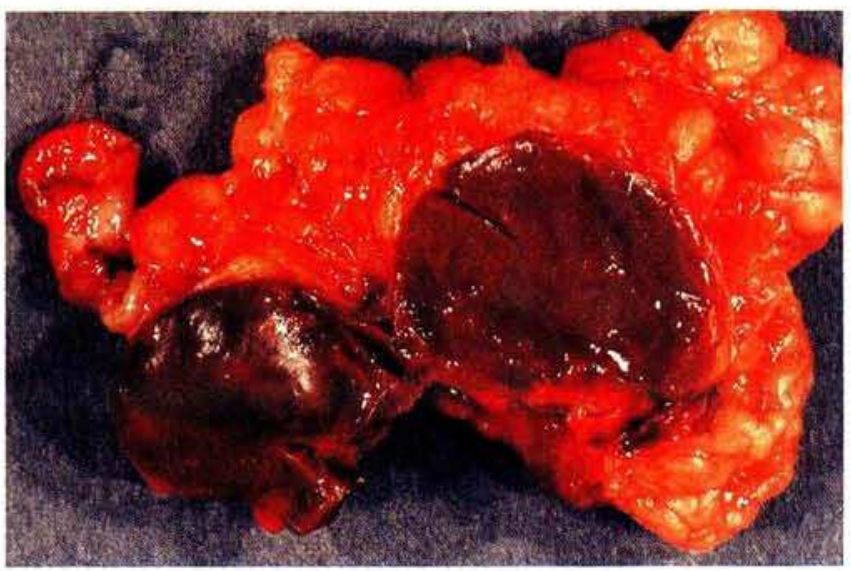

Figure 2: Resected part of the stomach, showing areas of lienal tissue. 
Ectopic spleen is a rare condition that is difficult to diagnose, especially when the spleen is located in the digestive tract. Ultrasonography, arteriography, and additional scintigraphy are of particular value in the preoperative diagnostic management (3). In symptomatic cases, the treatment of choice has been local surgical resection.

W. Laszewicz, A. Baniukiewicz, E. Wróblewski

Dept. of Gastroenterology, Medical School, Białystok, Poland

\section{References}

1. Lamesch P, Lamesch A. Anomalies of the position of the spleen in the child: case report and review of the literature from 1896 to 1990. Langenbecks Arch Chir 1993; 378: 171-7.
2. Angeras U, Almskog B, Lukes P, Lundstam S, Weiss L. Acute gastric hemorrhage secondary to wandering spleen. Dig Dis Sci 1984; 29: 1159-63.

3. Riebel T, Lambrecht W, Amon O, Bromel T. Torquierte Wandermilz. Monatsschr Kinderheilkd 1985; 133: 300-3.

Corresponding Author

W. Łaszewicz, M.D.

Dept. of Gastroenterology, Medical School

M.C. Skłodowskiej 24a, 15-276 Białystok

Poland 